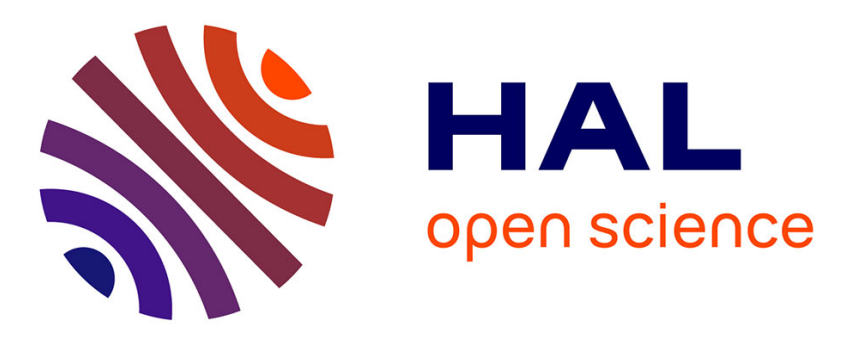

\title{
Colloidal and Supported TiO 2: Toward Nonextractable and Recyclable Photocatalysts for Radical Polymerizations in Aqueous Dispersed Media
}

\author{
Emeline Lobry, Abdoul Salam Bt Bah, Loïc Vidal, Esther Oliveros, André \\ Braun, Adrien Criqui, Abraham Chemtob
}

\section{To cite this version:}

Emeline Lobry, Abdoul Salam Bt Bah, Loïc Vidal, Esther Oliveros, André Braun, et al.. Colloidal and Supported TiO 2: Toward Nonextractable and Recyclable Photocatalysts for Radical Polymerizations in Aqueous Dispersed Media. Macromolecular Chemistry and Physics, 2016, 217 (20), pp.2321-2329. 10.1002/macp.201600150 . hal-02442169

\section{HAL Id: hal-02442169 https://hal.science/hal-02442169}

Submitted on 16 Jan 2020

HAL is a multi-disciplinary open access archive for the deposit and dissemination of scientific research documents, whether they are published or not. The documents may come from teaching and research institutions in France or abroad, or from public or private research centers.
L'archive ouverte pluridisciplinaire HAL, est destinée au dépôt et à la diffusion de documents scientifiques de niveau recherche, publiés ou non, émanant des établissements d'enseignement et de recherche français ou étrangers, des laboratoires publics ou privés. 
DOI: $10.1002 /$ macp.

Article Type: Full Paper

\section{Colloidal and Supported $\mathrm{TiO}_{2}$ : Towards Non-Extractable and Recyclable Photocatalysts for Radical Polymerizations in Aqueous Dispersed Media}

Emeline Lobry, Abdoul Salam BT Bah, Loïc Vidal, Esther Oliveros, André M. Braun, Adrien

Criqui, Abraham Chemtob*

Dr. E. Lobry, A. S. BT Bah

Laboratory of Macromolecular Photochemistry and Engineering

University of Haute-Alsace

3 rue Alfred Werner, 68093 Mulhouse Cedex, France

Dr. E. Oliveros

Laboratoire des Interactions Moléculaires et Réactivité Chimique et Photochimique (IMRCP), UMR 5623-CNRS/UPS

Université Toulouse III Paul Sabatier

118, route de Narbonne, 31062 Toulouse Cedex 9, France.

Dr. A. M. Braun

Engler-Bunte-Institute

Karlsruhe Institute of Technology

76131 Karlsruhe, Germany

Dr. A. Criqui

Mäder Research

MADER GROUP

130 rue de la Mer Rouge, 68200 Mulhouse, France

Dr. A. Chemtob, Loïc Vidal

Institut de Science des Matériaux de Mulhouse

CNRS UMR 7361

University of Haute-Alsace

15 rue Jean Starcky, 68057 Mulhouse, France

E-mail: abraham.chemtob@uha.fr

*Corresponding author: Tel: +33 3896088 04; abraham.chemtob@uha.fr

\section{Abstract}


Two high surface area titania forms, dispersed as stable nanoparticles or coated on fused silica microfiber, are used as non-leachable photocatalysts for the radical photopolymerization of methyl methacrylate miniemulsion in water. At low loading $\left(0.17 \mathrm{wt} \% / \mathrm{wt}_{\text {monomer }}\right)$, both nanoscale $\mathrm{TiO}_{2}$ yield ca. 50\% conversion after 10 min UV irradiation, compared to $63 \%$ with a conventional type I photoinitiatior (hydroxyacetophenone). High-molecular-weight values (> $180 \mathrm{kDa}$ ) and a polydispersity index of about 1.5 are achieved, indicating that undesirable degradation is negligible. In the proposed mechanism, a surface initiation takes place through the generation of hydroxyl radicals from $\mathrm{H}_{2} \mathrm{O}$ oxidation. We show that irradiance and $\mathrm{TiO}_{2}$ content are two key parameters for controlling molecular weight and conversion values. The supported $\mathrm{TiO}_{2}$ form can be easily recovered and reused up to 4 times, despite a gradual reduction in conversion. Deposited on the wall of the annular photochemical reactor, it enables reaction scaling-up.

\section{FIGURE FOR ToC_ABSTRACT}

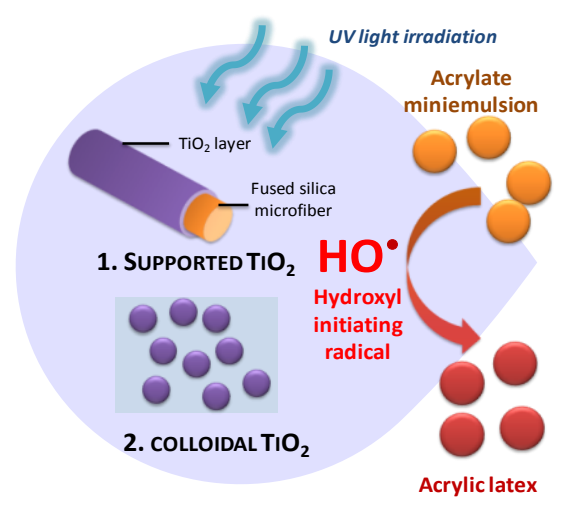




\section{Introduction}

Issues including initiator odor, toxicity, migration and contamination, which may affect the properties or uses of polymer products, are currently at the centre of public debate, especially in the context of consumer and worker protection. The problem is particularly acute in UVcuring technology, which is used for the large-scale production of industrial coatings, adhesives, inks and other photosensitive materials. ${ }^{[1,2]}$ Free radical UV-curing is characterized by sub-second cycle times and the need of high photoinitiator (PI) concentrations to overcome oxygen inhibition, especially in fields such as the printing industry. This leads to a significant amount of non-reacted PI remaining in cross-linked films. Due to their low-molecular-weight, PIs are able to migrate within the film network, and may extract from the surface. In the field of food packaging, this mechanism may result in contamination, and spawned the important food product scandals of recent years which have permanently affected the consciousness and driven more stringent regulations. ${ }^{[3]}$

At present, the main response of the industry concerns the development of polymer initiating systems based on oligomeric type II PIs, hence avoiding the release of low-molecular-weight photoproducts. These initiating systems typically involve a couple of non-migratory oligomeric photosensitizers (based on thioxantone or benzophenone ${ }^{[4]}$ ) and a hydrogen donor (polymeric amine) generating initiating species of high-molecular-weight. ${ }^{[5]}$ However, these "polymeric" PIs involve additional cost, lead to higher viscosities of the UV-curable formulations, and decrease polymerization reactivity when used at similar weight ratios as low-molecular-weight analogues.

To overcome these limitations, semiconductor nanoparticles have been recently presented as potential non-migrating radical photoinitiators. ${ }^{[6]}$ However, the capacity of semiconductors such as $\mathrm{TiO}_{2}, \mathrm{ZnO}$ or $\mathrm{CdS}$ to act as initiator of radical photopolymerization was already demonstrated several decades ago. ${ }^{[7-12]}$ Today, nanoscale semiconductor particles, especially nanoTiO 2 , are best known as photocatalysts for advanced oxidation processes (AOP). ${ }^{[13,14]}$ 
$\mathrm{TiO}_{2}$-photocatalysis is induced by the generation of excitons (electron-hole pairs) upon absorption of UV-radiation by the semiconductor leading to redox reactions of compounds adsorbed at the particles surfaces, e.g. molecular oxygen $\left(\mathrm{O}_{2}\right)$ and/or water. The resulting reactive oxygen species (ROS), i.e., hydroxyl radical (HO') cause oxidation and subsequent mineralization of organic contaminants present in water or air. ${ }^{[15]}$ Superoxide radical anion $\left(\mathrm{O}_{2}{ }^{-}\right)$, generated by the reduction of $\mathrm{O}_{2}$, might act as a reductant but is not known to induce subsequent radical reactions. Based on the premise that some ROS, such as $\mathrm{HO}$, might initiate radical polymerizations, Kraeutler et al. demonstrated as early as 1979 that fumed $\mathrm{TiO}_{2}$ could replace a PI when dispersed in an organic solvent containing methyl methacrylate (MMA). ${ }^{[16]}$ Mechanistically, it might be assumed that the holes of the electronically excited $\mathrm{TiO}_{2}$ react by electron transfer with an alcohol $(\mathrm{ROH})$ or a carboxylate $\left(\mathrm{RCOO}^{-}\right)$added as coinitiator, thus generating $\mathrm{C}$-centered radicals $\left(\mathrm{R}^{\cdot}\right)$ either by loss of a proton (primary or secondary $\mathrm{ROH}$ ) or by loss of $\mathrm{CO}_{2}$ from the intermediary RCOO'. Such initiating systems based on a semiconductor nanoparticle/coinitiator tandem have attracted considerable interest in radical photopolymerization. ${ }^{[17-25]}$ Nevertheless, non-reacted co-initiators may be prone to migration in contrast to nanometer scale semiconductor particles that are not supposed to diffuse in the polymer network. Alternative pathways involving semiconductor nanoparticles proceeded by photoinduced electron transfer to transition metal ions to trigger atom-transfer radical polymerization (ATRP) ${ }^{[25,26]}$ or bulk radical polymerization using surface $\mathrm{Pt}(\mathrm{II}), \mathrm{Cu}(\mathrm{II})$ or Fe(III) modified ZnO nanoparticles. ${ }^{[6]}$

Yet, the simplest method to avoid the formation of residual migrating species is probably to rely on hole oxidation of water to create initiating hydroxyl radicals (HO') that are known to be very effective for the oxidation of organic compounds in aqueous solution. The first $\mathrm{TiO}_{2}-$ photocatalyzed polymerization studies were performed in aqueous solution using dispersed titania powder. This restricted the scope of this approach to a short list of water-soluble 
monomers (acrylamide, ${ }^{[8,24,27]}$ acrylic acid ${ }^{[27]}$ or methacrylic acid ${ }^{[28]}$ ) or partially water-soluble monomers (MMA). ${ }^{[22,29,30]}$

Given that most utility monomers are insoluble in water, we suggest that polymerization in aqueous dispersed media may be a more convenient and versatile system to perform nanoscale $\mathrm{TiO}_{2}$-photoinitiated polymerizations without generation of migrating photoproducts. Currently, polymerization in dispersed media accounts for nearly $20 \%$ of the worldwide polymer production, and encompasses a number of distinct processes. Mainly suspension and emulsion processes have been used industrially to produce some of the most important commodity thermoplastics, including poly(vinyl chloride) or styrene-acrylic polymers. Recently, Song et al. showed that solid $\mathrm{TiO}_{2}$ nanoparticles can act both as photocatalyst and Pickering stabilizer (by adsorption on droplet surface) in emulsion polymerization of styrene. ${ }^{[31,32]}$

Keeping this study in mind, we investigated in a first step a model MMA miniemulsion to confirm the feasibility of a $\mathrm{TiO}_{2}$-photoassisted polymerization in an aqueous dispersed medium. But in all likelihood, this approach may be applied to a range of aqueous monomer emulsions. By a careful control of the amount of added $\mathrm{TiO}_{2}$ and the conditions of irradiation, we could show that the production of high-molecular-weight acrylic latex can be achieved without substantial chain degradation. In this work, two nanoscale $\mathrm{TiO}_{2}$ forms have been investigated, as depicted in Figure 1: colloidal dispersion and nanosized layer coated on fused quartz fiber. Both systems have specific advantages, and their initiating efficiencies have been compared to that of a conventional water-soluble type I PI.

1. Colloidal $\mathrm{TiO}_{2}$ offers significant process advantages: direct addition to any aqueous monomer dispersion without emulsification or dissolution stage, high surface-to-volume ratio to ensure optimal reactivity, and small average particle diameter $(\approx 30 \mathrm{~nm})$ to limit scattering and attenuation of UV radiation. However, the catalyst cannot be extracted after the latex 
synthesis stage. This raises concern on the UV photostability of the final product (waterborne coating or adhesive), in particular for outdoor applications.

2. $\mathrm{TiO}_{2}$-coated quartz fiber can act as a "supported" catalyst. ${ }^{[33]}$ Quartz fibers offer an inert and UV transparent support, while the thin $\mathrm{TiO}_{2}$ layer deposited on the micrometric fiber may provide a specific surface area for an optimal contact with the monomer emulsion and high reactivity. Supported $\mathrm{TiO}_{2}$ may be seen as a promising avenue for recoverable and reusable PIs, lessening the environmental footprint of photopolymerization reactions. The main challenge is the risk of fouling of the fiber surface during photopolymerization, suppressing the photocatalytic activity.
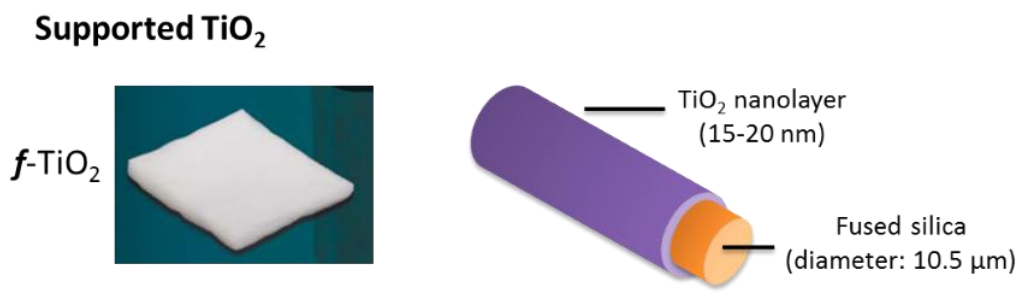

Colloidal $\mathrm{TiO}_{2}$ dispersion in water
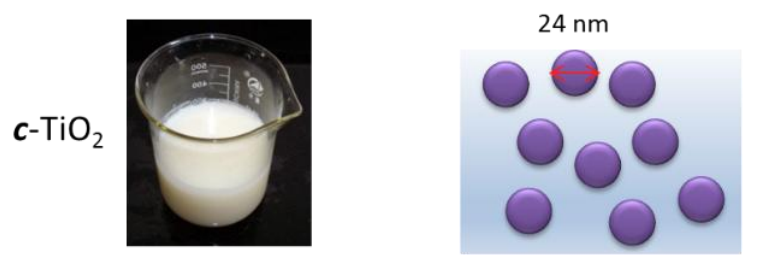

Figure 1. Supported and colloidal $\mathrm{TiO}_{2}$ as photocatalysts for photoinitiation of radical polymerization of monomer aqueous emulsions

\section{Materials and methods}

\subsection{Materials}

Technical grade methyl methacrylate (MMA) was purchased from Aldrich and used without further purification. Octadecyl acrylate (OA, Aldrich) was employed as co-stabilizer of monomer miniemulsions and sodium dodecyl sulfate (SDS, Aldrich) was used as a surfactant for preparing the MMA miniemulsions. Distilled water was used in the preparation of the miniemulsions. Used for comparison, the conventional type I water-soluble PI, Irgacure 2959 (2-hydroxy-1-[4-(2-hydroxyethoxy)phenyl]-2-methyl-1-propanone), was provided by BASF 
Specialty Chemicals. Nanoscale titanium dioxide was used in two different forms, (i) as a dispersion in water (33-37 wt $\%$, specific surface area of $49 \mathrm{~m}^{2} / \mathrm{g}$ ) produced by Buehler and sold by Aldrich. According to manufacturer information, this stable colloidal dispersion has an average diameter lower than $30 \mathrm{~nm}$, and $90 \%$ of the size distribution lies below the threshold value of $150 \mathrm{~nm}$. (ii) as a $\mathrm{TiO}_{2}$-coated fused silica fiber provided by Saint Gobain (Quartzel® PCO). Currently used for air or water treatment, this product consists of a felt composed of entangled fiberglass with a nominal $\mathrm{TiO}_{2}$ thickness of $15-20 \mathrm{~nm}$, and a specific surface area of ca. $120 \mathrm{~m}^{2} / \mathrm{g}$.

\subsection{Miniemulsion photopolymerisation}

The formulation of the $20 \mathrm{wt} \%$ solids content monomer miniemulsion is described in Table $\mathbf{1 .}$ In a typical procedure, an organic phase was first prepared by dissolving the co-stabilizer (OA, $\left.4 \mathrm{wt} \% / \mathrm{wt}_{\mathrm{monomer}}\right)$ into the monomer. The latter was then added to an aqueous SDS solution ( $\left.2 \mathrm{wt} \% / \mathrm{wt}_{\text {monomer }}\right)$. Both phases were then stirred during $10 \mathrm{~min}$ at $700 \mathrm{rpm}$. The resulting coarse macroemulsion was then sonicated during 5 min using a Branson Sonifier $450(450 \mathrm{~W} / \mathrm{L})(9$ output control, $80 \%$ duty cycle) while maintaining the stirring. The PI was introduced differently depending on its structure. The water-soluble type I initiator or colloidal $\mathrm{TiO}_{2}$ were simply added to the aqueous phase before the emulsification stage. As regards to the $\mathrm{TiO}_{2}$-coated fiber glass, the fabric was introduced in the reactor vessel containing the monomer miniemulsion just before irradiation. In the three cases, the weight concentration of the photochemically reactive substance (molecular $\mathrm{PI}$ or $\mathrm{TiO}_{2}$ ) was kept constant with respect to the monomer content in order to enable comparison. Regarding $\boldsymbol{c}$ $\mathrm{TiO}_{2}$, the concentration in $\mathrm{TiO}_{2}$ can be easily deduced from the solids content value. For $f$ $\mathrm{TiO}_{2}$, the mass content was estimated based on the $\mathrm{TiO}_{2}$ weight content compared to the total weight obtained from Energy-dispersive X-ray spectroscopy (EDX) data. 
Table 1. Miniemulsion formulation

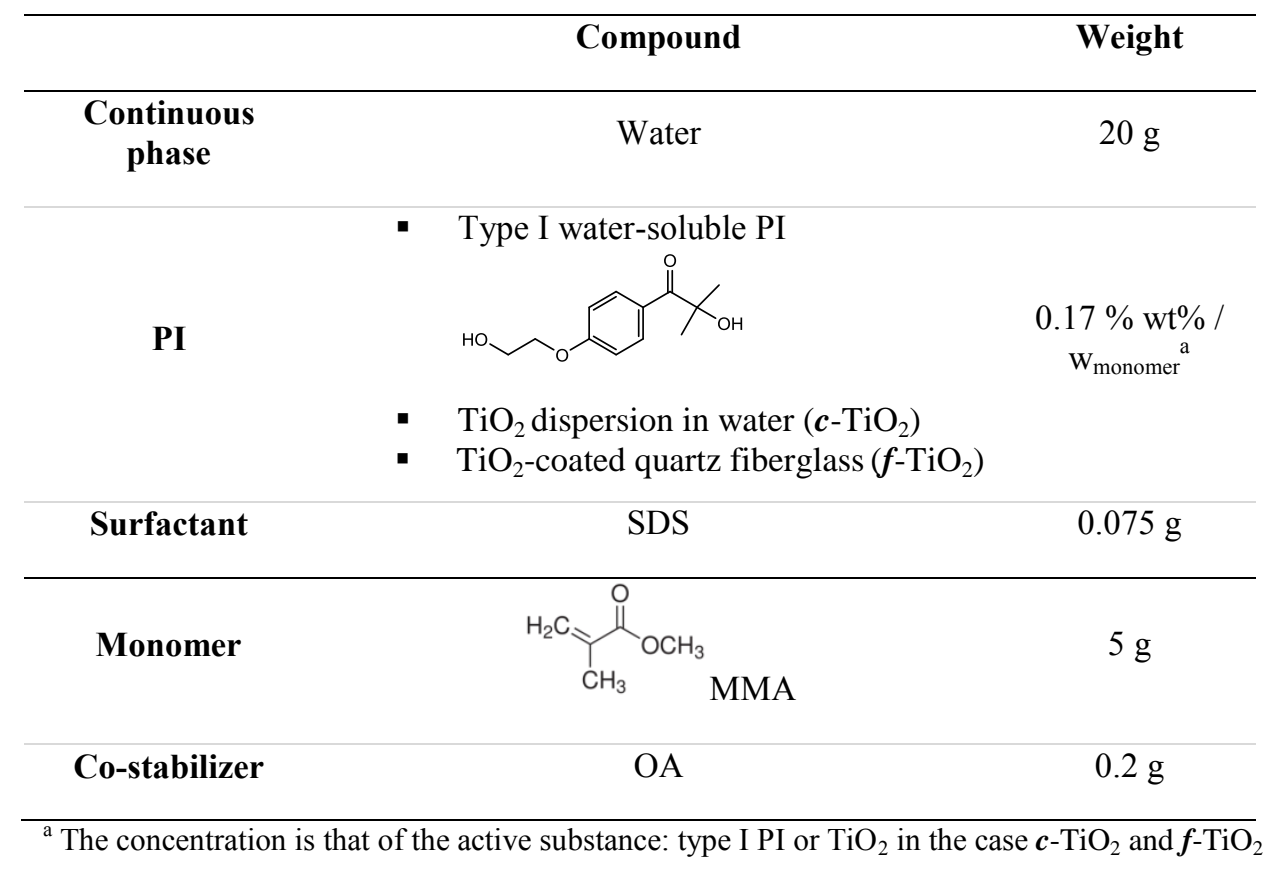

Figure 2 depicts the photopolymerization set-up. The reaction was performed in a $1 \mathrm{~mm}$-thick quartz rectangular cell $(340 \mu \mathrm{L})$ without stirring and without degassing except when explicitly mentioned. Polychromatic irradiation was applied vertically using a focused beam generated by a medium-pressure $\mathrm{Hg}$-Xe arc lamp (Hamamatsu L8252, $365 \mathrm{~nm}$ reflector, $200 \mathrm{~W}$ ) coupled to a flexible light-guide. Adverse effects from heat (IR radiation) were removed by a $365 \mathrm{~nm}$ elliptical cold reflector. Irradiation below $310 \mathrm{~nm}$ was removed using a glass filter to avoid self-initiation of acrylate monomers. An irradiance of $430 \mathrm{~mW} \mathrm{~cm}{ }^{-2}$ for the spectral range $310-600 \mathrm{~nm}$ was measured by a radiometer (Ocean Optics HR4000 spectrometer) at the surface of the sample at full opening of the diaphragm. The light was tuned by varying the opening of the diaphragm. 


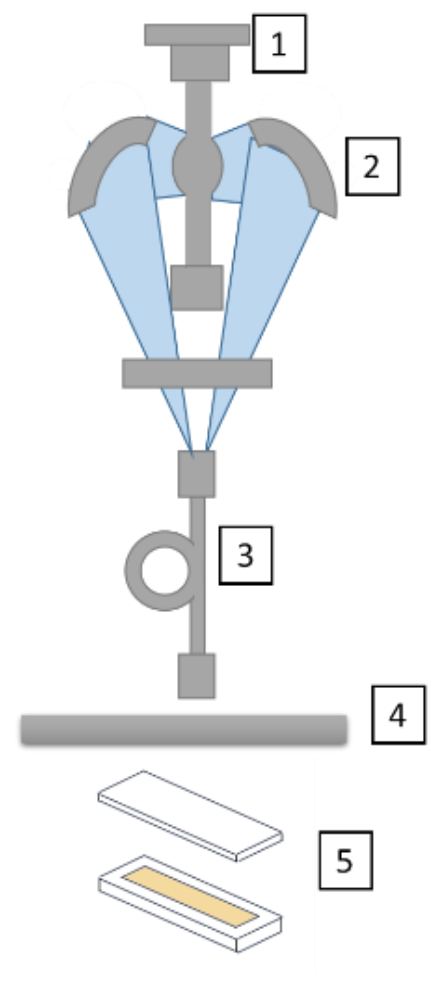

Figure 2. Experimental set-up for miniemulsion photopolymerization 1. Medium pressure $\mathrm{Xe}-\mathrm{Hg}$ arc lamp, 2. Long-wave elliptical reflector, 3. Light guide, 4. Glass filter, 5. Spectroscopic cuvette with an optical path of $1 \mathrm{~mm}$ containing the miniemulsion

A scale-up of the $f$ - $\mathrm{TiO}_{2}$-induced photopolymerization was performed in batch using an annular photochemical reactor (Peschl Ultraviolet $\left.{ }^{\circledR}\right)$. A standard medium pressure $\mathrm{Hg}$ arc lamp (Heraeus Noblelight TQ 150, arc length: $4.4 \mathrm{~cm}$ ) emitting a series of rays from $250 \mathrm{~nm}$ to $600 \mathrm{~nm}$ is used for irradiation. The lamp is housed in a fused borosilicate sleeve to avoid irradiation at wavelengths below $310 \mathrm{~nm}$. Because of the important IR-emission of the lamp, an external cooling jacket keeps the photoreactor contents at a temperature between 20 and 25 ${ }^{\circ} \mathrm{C}$ throughout the polymerization reaction. The combination of lamp, sleeve and cooling device is introduced into the cylindrical reactor vessel made of borosilicate accommodating up to $120 \mathrm{~mL}$ of monomer miniemulsion. The distance between the two annular sections (external sleeve wall and inner reactor wall) is $9 \mathrm{~mm}$ and defines the optical path length. Magnetic stirring of the miniemulsion is maintained throughout the photochemically initiated polymerization. Samples were drawn during polymerization to determine conversion.

\subsection{Characterization}


The average diameter of the monomer droplets $\left(D_{d}\right)$, latex particles $\left(D_{p}\right)$ and colloidal $\mathrm{TiO}_{2}$ particles were measured by dynamic light scattering (DLS) using a Zetasizer nano ZS (Malvern Instruments). Conversion was assessed by gravimetric analysis. Molecular weights of the different latexes prepared were determined by size exclusion chromatography by using a PL-gel mixed D $(5 \mu \mathrm{m}, 300 \mathrm{~mm} \times 7.5 \mathrm{~mm})$ Shimadzu column calibrated with polystyrene. The molecular weights provided are then given in polystyrene equivalent. Both types of $\mathrm{TiO}_{2}$ were characterized by X-ray diffraction (XRD, Philips X'Pert Pro PAnalytical). Transmission electron microscopy (TEM) was carried out on a Philips CM200 microscope operating at 30 $\mathrm{kV}$. Scanning electron microscopy (SEM) was carried out on a Jeol JCM 6000 microscope operating at $15 \mathrm{kV}$. Quartzel ${ }^{\circledR}$ fibers were analyzed before and after photopolymerization and the $\mathrm{TiO}_{2}$ content was measured by EDX.

\section{Results and discussion}

\subsection{Characterization of colloidal and supported nanoscale $\mathrm{TiO}_{2}$}

Colloidal $\mathrm{TiO}_{2}\left(\boldsymbol{c}\right.$ - $\left.\mathrm{TiO}_{2}\right)$ and $\mathrm{TiO}_{2}$-coated fiberglass $\left(\boldsymbol{f}-\mathrm{TiO}_{2}\right)$ were characterized by a range of techniques prior to their use. All data are summarized in Table 2. Concerning the morphology of $\boldsymbol{f}-\mathrm{TiO}_{2}$, the SEM analysis showed an entangled, curly continuous fiber structure displaying a mean fiber diameter of $10.5 \mu \mathrm{m}$. Fiber surface appeared smooth and default-free, i.e. without any area non-covered by the titanium dioxide layer (15-20 $\mathrm{nm}$ thickness according to the manufacturer). EDX analysis revealed a $\mathrm{TiO}_{2}$ concentration of 1.4 wt\% (see Figure $\mathbf{S 1}$ in Supporting Information). TEM analysis of $\boldsymbol{c}$ - $\mathrm{TiO}_{2}$ showed an ensemble of non-spherical particles that are roughly $24 \mathrm{~nm}$ in diameter. In contrast, DLS showed a much greater (hydrodynamic) average diameter $(90 \mathrm{~nm})$. TEM provides information about particles which are dehydrated and immobilized on a solid support. This can lead to structural distortions compared to the solvent swollen state of DLS analysis. Discrepancy between DLS and TEM size data is not necessarily contradictory; it may emphasize that inorganic nanoparticles like 
$\mathrm{TiO}_{2}$ are prone to aggregation due to strong Van der Waals interactions. Additionally, TEM provides information about the high crystalline structure of the individual nanoparticles. The two main physico-chemically distinct polymorphs of $\mathrm{TiO}_{2}$ are anatase and rutile. The precise crystalline phase was determined by XRD analysis (see Figure $\mathbf{S 2}$ of $\mathrm{SI}$ ): $\boldsymbol{c}$ - $\mathrm{TiO}_{2}$ has a pure anatase structure that is known to have a higher photocatalytic activity than rutile but is thermodynamically less stable. ${ }^{[34,35]}$ By contrast, the XRD pattern of $f-\mathrm{TiO}_{2}$ revealed a coexistence of the two different crystallographic forms rutile/anatase in the ratio: ca. 80:20\%.

Table 2. Main characteristics of the two nanoscale $\mathrm{TiO}_{2}$, either coated on amorphous silica fiber $\left(\boldsymbol{f}-\mathrm{TiO}_{2}\right)$ or dispersed in water as nanoparticles $\left(\boldsymbol{c}-\mathrm{TiO}_{2}\right)$

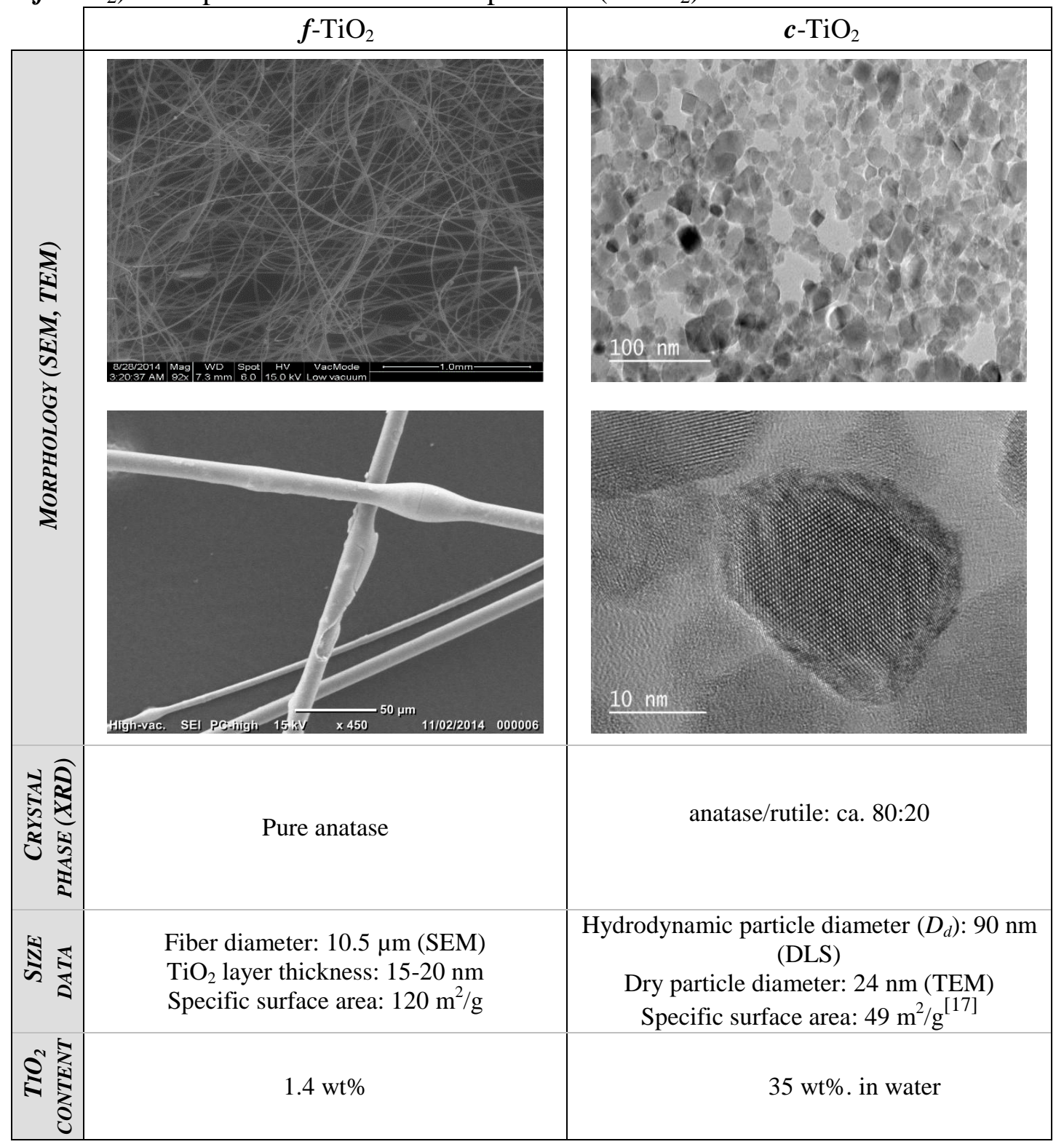




\subsection{Nanoscale $\mathrm{TiO}_{2}$-assisted photopolymerization of a MMA miniemulsion}

Table 3 compares conversions, molecular weights, and particle sizes of the products obtained by the photopolymerization of a MMA miniemulsion $\left(D_{d}=50 \mathrm{~nm}\right)$ irradiated during 10 min in presence of $\boldsymbol{f}-\mathrm{TiO}_{2}, \boldsymbol{c}-\mathrm{TiO}_{2}$ or of a conventional type I PI (hydroxyacetophenone). All photopolymerizations were performed in a 1-mm thick spectroscopic cell to optimize the irradiated volume fraction.

Table 3. Comparison between different initiation modes for the miniemulsion photopolymerization of MMA. Irradiation conditions: Hg-Xe lamp, $430 \mathrm{~mW} / \mathrm{cm}^{2}, 310-600$ nm, $10 \mathrm{~min}$.

\begin{tabular}{ccccc}
\hline PI & $\begin{array}{c}\text { Conv. } \\
\mathbf{\%}\end{array}$ & $\begin{array}{c}\boldsymbol{M}_{\boldsymbol{n}} \\
\mathbf{k D a}\end{array}$ & $\begin{array}{c}\boldsymbol{M}_{\boldsymbol{n}} / \boldsymbol{M}_{\boldsymbol{w}} \\
\text { PDI }\end{array}$ & $\begin{array}{c}\text { Particle size }^{\mathbf{a}} \\
\boldsymbol{D}_{\boldsymbol{p}}, \mathbf{n m}\end{array}$ \\
\hline Type I PI & 63 & 176 & 2.8 & 63 \\
$\boldsymbol{c}$ - $\mathrm{TiO}_{2}$ & 54 & 381 & 1.6 & 65 \\
$\boldsymbol{f}$-TiO & 43 & 181 & 1.4 & 56 \\
\hline${ }^{a}$ Determined by DLS & & & &
\end{tabular}

Both nanoscale $\mathrm{TiO}_{2}$ proved to be efficient PI, yielding ca. $50 \%$ conversions after 10 min of irradiation compared to $63 \%$ for a conventional PI. Control experiments without PI confirmed the absence of monomer consumption upon irradiation. Despite a greater surface area $(0.84$ $\mathrm{m}^{2}$ vs $\left.0.42 \mathrm{~m}^{2}\right), \boldsymbol{f}-\mathrm{TiO}_{2}$ yields lower conversion (43\%) compared to $\boldsymbol{c}$ - $\mathrm{TiO}_{2}(54 \%)$. To account for this result, we postulate that the immobilization of the catalyst may cause a less accessible surface area, and reduces the number of active catalyst sites compared to a finely dispersed $\boldsymbol{c}-\mathrm{TiO}_{2}$ system. A second most likely explanation is that the surface of $\boldsymbol{f}-\mathrm{TiO}_{2}$ absorbing the incident radiation may be smaller than the corresponding surface of $c-\mathrm{TiO}_{2}$ dispersed over the whole reactor volume. The $M_{n}$ values of the precipitated polymers are of the same order or even larger in the case of the photocatalyzed polymerization. The highmolecular-weight values rule out that significant oxidative degradation may occur, and may reflect a segregation (compartmentalization) effect. As two radicals species located in two separate particles are unable to react, the molecular weight can increase due to a decreased termination rate. In addition, the formation of low-molecular-weight products may be limited 
by slower oxidation reactions compared to propagation reactions, or by a rather small concentration of ROS. The latter interpretation seems to be the most likely reason considering the much narrower polydispersity index (ca. 1.5) for the $\mathrm{TiO}_{2}$-initiated samples. In contrast, the reference sample has a PDI value of 2.8 , more consistent with a conventional chain reaction (all the SEC traces are provided in Figure S3 in SI). Finally, the partially converted particles show size values very similar to those of the starting droplets, thus indicating a nucleation preferentially localized in the droplets. It must be emphasized that the number of monomer droplets in $\boldsymbol{c}-\mathrm{TiO}_{2}$ is about 290 times higher than the number of semiconductor nanoparticles. Consequently, the proportion of polymer/inorganic nanoparticles is assumed to remain much lower than pure polymer particles. With regard to this final point, a significantly lower concentration in $\mathrm{TiO}_{2}$ has been used compared to other studies in aqueous solution. ${ }^{[22,28]}$ One can expect that if photocatalyst particles were coated with polymer layer, the photocatalytic reactivity would be strongly reduced.

\subsection{A tentative photoinitiation mechanism}

While these first experiments illustrate the photoinitiation ability of nanoscale $\mathrm{TiO}_{2}$ in dispersed media, a precise mechanism needs to be established. In principle, superoxide radicals $\left(\mathrm{O}_{2}^{\bullet-}\right)$ generated by a transfer of electrons from the conduction band to $\mathrm{O}_{2}$ (reductive pathway), or hydroxyl radicals $\left(\mathrm{OH}^{\bullet}\right)$ resulting from electron transfer from $\mathrm{H}_{2} \mathrm{O}$ to "holes" in the valence band (oxidative pathway (1) may both initiate radical polymerization (Figure 2), provided that $\mathrm{O}_{2}{ }^{\bullet-}$ and its protonated form would not dismutate to $\mathrm{H}_{2} \mathrm{O}_{2}$ (Figure 3). A final possibility would imply the oxidation of MMA (oxidative pathway (2)) by "holes of the valence band and deprotonation to yield initiating $\mathrm{C}$-centered radicals of the monomer substrate. 


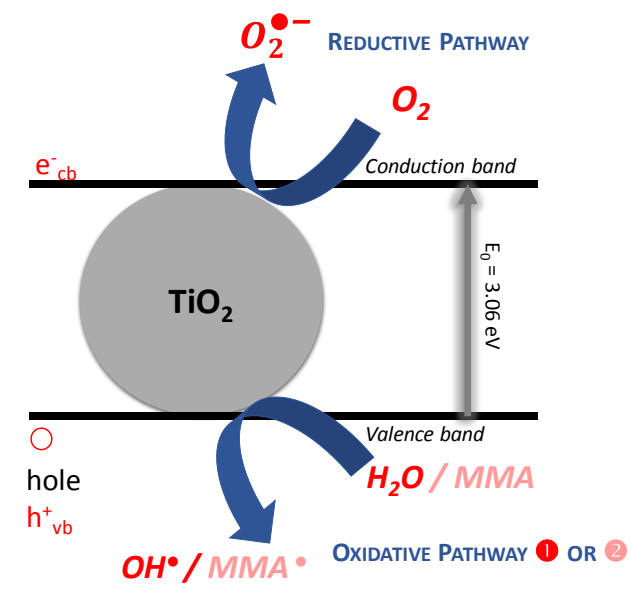

Figure 3. Photocatalytic activity of $\mathrm{TiO}_{2}$

To shed light into the initiation pathway, $\mathrm{O}_{2}$ or water were removed from the formulation respectively by nitrogen purging or by substituting water with acetonitrile. Removal of dissolved $\mathrm{O}_{2}$ led to an increase of conversions from 54 to $60 \%\left(c-\mathrm{TiO}_{2}\right)$ and from 43 to $55 \%$ $\left(\boldsymbol{f}-\mathrm{TiO}_{2}\right)$, thus confirming the negligible role played by the superoxide anions $\left(\mathrm{O}_{2}{ }^{\bullet-}\right)$ in polymerization initiation. However, oxygen is not the only species able to be reduced by the electron in the conduction band. Among the other compounds present, it seems that only the carboxylate of MMA and the sulfate group of SDS are electron acceptors. The transfer of an electron to MMA would produce an anion radical that is protonated, the resulting allylic radical could be a weak initiator. The transfer of an electron to SDS would produce the dodecyl alcoholate and the radical of sulfurous acid anion that would instantly dimerize to dithionic acid, itself a weak oxidizing and reducing agent. Unless we would find sulfate by ion chromatography, we would have to assume that MMA is the electron acceptor. If this is the case, a slight acceleration of the polymerization could be only observed, meaning MMA reduction is not the main initiation reaction. The most likely explanation for the slight increase in conversion in the $\mathrm{O}_{2}$-free experiment is related to the suppression of the inhibition by oxygen. This means that the formation of less reactive $\mathrm{ROO}^{\bullet}$ radicals unable to add on new monomer molecules is prevented. 
In addition, a solution of MMA in anhydric acetonitrile failed to photopolymerize $(0 \%$ conversion) in presence of $\boldsymbol{f}-\mathrm{TiO}_{2}$, revealing the minor contribution of oxidation of acrylate molecules by "holes" of the valence band to photopolymerization (pathway (2)). This set of experiments suggests that the presence of water is a prerequisite for the formation of initiating species, which are in all likelihood highly reactive hydroxyl radicals (pathway (1)). A tentative mechanism would therefore involve $\mathrm{OH}^{\bullet}$ primarily generated at the surface of the semiconductor. Despite their limited lifetime and diffusion ability, a rather large fraction of $\mathrm{OH}^{\bullet}$ may react with MMA at the aqueous/organic interface of the dispersed medium. Subsequently, the C-centered MMA-radicals add to other MMA molecules present at high local concentration within the monomer droplets.

\subsection{Primary process parameters affecting the $\mathrm{TiO}_{2}$ photocatalyzed polymerization of} MMA

Irradiance. As summarized in Table 4, a decrease of irradiance from 430 to $115 \mathrm{~mW} / \mathrm{cm}^{2}$ reduces the final conversion from $82 \%$ to $58 \%$ in 10 minutes, and slightly affects the molecular weight values (ca. $500 \mathrm{kDa}$ ). For reaction systems implying $\boldsymbol{c}$ - $\mathrm{TiO}_{2}$, we observe a strong discrepancy between droplet size $(50 \mathrm{~nm})$ and particle size $(85-155 \mathrm{~nm})$, but the presence of $\mathrm{TiO}_{2}$ particles may distort the final particle size value because of its propensity to form aggregates. The effect of irradiance is much more pronounced in the case of $f-\mathrm{TiO}_{2}$. At $115 \mathrm{~mW} / \mathrm{cm}^{2}$, the conversion is only $20 \%$ versus $43 \%$ at $430 \mathrm{~mW} / \mathrm{cm}^{2}$. This result translates a much lower concentration of initiating radicals causing a significant increase of $\mathrm{M}_{\mathrm{n}}$. Given the fact that the efficiency of electronic excitation is much higher in nanoparticulate suspension that at immobile surfaces, the strong dependence of irradiance on the conversion of $f$ - $\mathrm{TiO}_{2}$ was expected. 
Table 4. Effect of irradiance on MMA miniemulsion photopolymerization initiated by $\operatorname{nanoTiO}_{2}\left(D_{d}=50 \mathrm{~nm}\right)$

\begin{tabular}{cccccc}
\hline $\begin{array}{c}\text { Nanoscale } \mathbf{T i O}_{\mathbf{2}} \\
\mathbf{w t} \% / \mathbf{w t}_{\text {monomer }}\end{array}$ & $\begin{array}{c}\text { Irradiance } \\
\mathbf{m W} \mathbf{~ c m}^{-\mathbf{2}}\end{array}$ & $\begin{array}{c}\mathbf{C o n v} \\
\mathbf{\%}\end{array}$ & $\begin{array}{c}\mathbf{M}_{\mathbf{n}} \\
\mathbf{k D a}\end{array}$ & $\mathbf{P D I}$ & $\begin{array}{c}\mathbf{D}_{\mathbf{p}} \\
\mathbf{n m}\end{array}$ \\
\hline & 430 & 82 & 499 & 1.7 & 95 \\
& 335 & 76 & 548 & 1.6 & 85 \\
$\boldsymbol{c}-\mathrm{TiO}_{2}$ & 295 & 67 & 404 & 2.1 & 135 \\
$3.88 \%$ & 180 & 66 & 586 & 1.5 & 95 \\
& 135 & 62 & 594 & 1.5 & 115 \\
& 115 & 58 & 535 & 1.7 & 95 \\
\hline & 430 & 43 & 181 & 1.4 & 56 \\
$\boldsymbol{f}-\mathrm{TiO}_{2}$ & 335 & 75 & 135 & 4.8 & 67 \\
$0.17 \%$ & 180 & 20 & 504 & 1.5 & 59 \\
& 115 & 20 & 548 & 1.5 & 52
\end{tabular}

$\mathrm{TiO}_{2}$ concentration. Regardless of the $\mathrm{TiO}_{2}$ morphology, variation of the catalyst concentration has a marked effect on conversion and molecular weight (Table 5). A higher $\mathrm{TiO}_{2}$ content enables the generation of a higher concentration of initiating species, yielding higher conversions and lower molecular weight values. However, it seems that $\boldsymbol{c}-\mathrm{TiO}_{2}$ conversion reached a threshold value. Above this value, the average molecular weight decreases. However, at the highest $\boldsymbol{f}-\mathrm{TiO}_{2}$ concentration $(0.2 \mathrm{wt} \%)$, much shorter chains were obtained as well as a broader molecular weight distribution $(\mathrm{PDI}=5.5)$, and these results may translate an increasing importance of degradation reactions. Particle sizes remain at a level close to those of droplets.

Table 5. Effect of the $\mathrm{TiO}_{2}$ content on the MMA miniemulsion photopolymerization

\begin{tabular}{|c|c|c|c|c|c|}
\hline & $\begin{array}{l}\text { Nanoscale } \mathrm{TiO}_{2} \\
\mathrm{wt} \% / \mathrm{wt}_{\text {monomer }}\end{array}$ & $\begin{array}{c}\text { Conv } \\
\%\end{array}$ & $\begin{array}{c}M n \\
\text { kDa }\end{array}$ & PDI & $\begin{array}{l}D_{p} \\
\mathrm{~nm}\end{array}$ \\
\hline \multirow{4}{*}{$f-\mathrm{TiO}_{2}$} & 0.07 & 15 & 641 & 1.4 & 60 \\
\hline & 0.08 & 35 & 877 & 1.3 & 61 \\
\hline & 0.16 & 43 & 181 & 1.4 & 56 \\
\hline & 0.20 & 49 & 108 & 5.5 & 60 \\
\hline \multirow{5}{*}{$\boldsymbol{c}-\mathrm{TiO}_{2}$} & 0.17 & 54 & 381 & 1.6 & 65 \\
\hline & 0.39 & 66 & 600 & 1.5 & 66 \\
\hline & 0.79 & 77 & 615 & 1.5 & 68 \\
\hline & 1.7 & 74 & 534 & 1.6 & 73 \\
\hline & 3.88 & 82 & 499 & 1.7 & 95 \\
\hline
\end{tabular}




\subsection{New potentialities of nanoscale $f-\mathrm{TiO}_{2}$ initiated photopolymerization}

$f-\mathrm{TiO}_{2}$ as recyclable $\mathrm{PI}$. In contrast to colloidal titania, immobilized $\boldsymbol{f}-\mathrm{TiO}_{2}$ system can be utilized to overcome the problem of post-process separation. A key feature of supported $\mathrm{TiO}_{2}$ is to offer facile recovery and separation. This section investigates the possibility of reuse of the photocatalyst for the photopolymerization in dispersed media, opening the way for a simple, low-cost, recyclable PI. Preliminary observations of the fibers before and after photopolymerization (Figure 4) reveal that a minor part of the synthesized PMMA can adhere to the fibers, which agrees with a surface-initiated reaction. This highlights the necessity for cleaning the microfibers before triggering a new photopolymerization. In the following recycling experiments, the fibers were systematically washed with THF, water, and dried overnight at $45^{\circ} \mathrm{C}$.
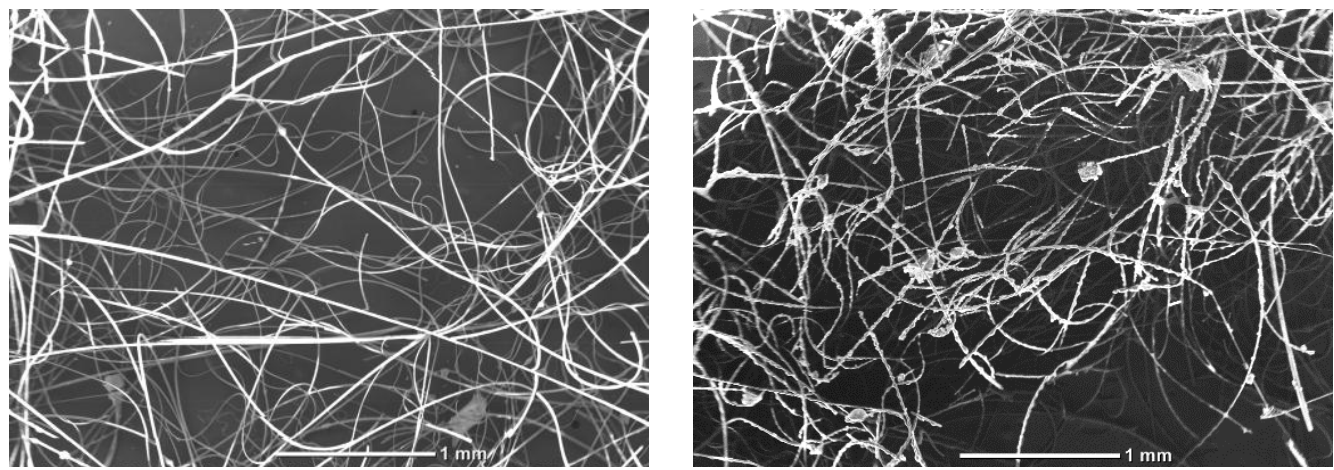

Figure 4. SEM pictures of the $f-\mathrm{TiO}_{2}$ before (left) and after (right) MMA miniemulsion photopolymerization

Figure 5 depicts the evolution of monomer conversion following 4 consecutive polymerizations. While the final conversion is relatively preserved after 2 cycles, a significant decrease is observed from $40 \%$ to $26 \%$ in the last two cases. The reduction in conversion reflects a decreased photocatalytic activity due to a diminished surface area (PMMA coating), but also to a loss of fiber materials after the washing process. A weight loss of approximately of $20 \mathrm{wt} \%$ was estimated between the first and the fourth experiments. Additionally, one must note that particle size remains constant $(58-63 \mathrm{~nm})$ regardless of the number of cycles. In 
contrast, the molecular weight increases from $181 \mathrm{kDa}$ in the first experiment to $437 \mathrm{kDa}$ for the last one, with a PDI value of about 1.5.

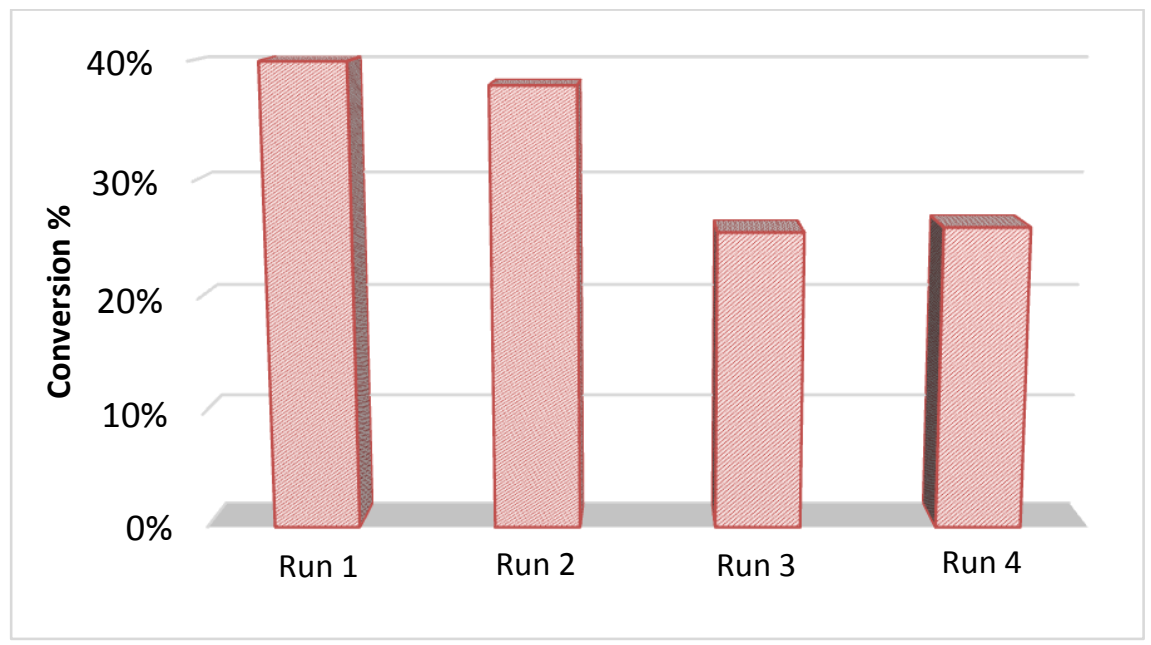

Figure 5. MMA conversion obtained during the photopolymerization of MMA miniemulsion when recycling $f-\mathrm{TiO}_{2}$

\section{Photopolymerization in annular batch photoreactor.}

To show scaling-up capacity of $\mathrm{TiO}_{2}$-assisted polymerization, MMA miniemulsion photopolymerization was also performed in a $120 \mathrm{~mL}$ photochemical reactor (see experimental section for details). The $f-\mathrm{TiO}_{2}$ felt was placed on the internal wall of the photoreactor to optimize light absorption. Figure 6 describes the evolution of the conversion with irradiation time. The conversion increases gradually and reached $84 \%$ after 100 min of irradiation. The molecular weight reached $425 \mathrm{kDa}$ with a PDI of 1.6. It is noteworthy that no destabilization of the particles was noticed. 


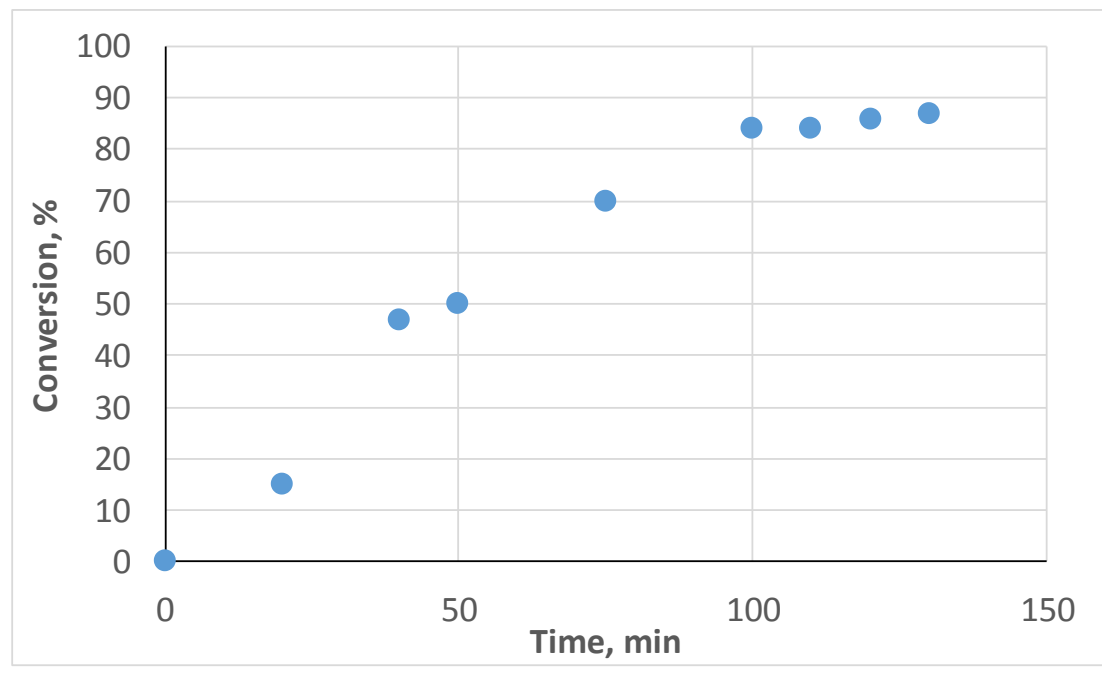

Figure 6. Conversion versus time plot of a $f-\mathrm{TiO}_{2}$ initiated $\mathrm{MMA}$ miniemulsion photopolymerization using a batch photoreactor:

\section{Conclusions}

Due to their inherently large ratio of surface area to volume and the high efficiency of absorption of UV light, colloidal titania and titania deposited on fused silica fiber have been intensively used in the domain of photocatalysis. The idea behind this study was to prove that these beneficial properties can also be used in photopolymerizations of aqueous emulsions containing acrylate monomers. High molecular weight PMMA chains with a relatively narrow polydispersity index of about 1.5 were achieved using two different $\mathrm{TiO}_{2}$ nanoscale forms (colloidal and supported titania). This new initiation mode combines the advantages of miniemulsion photopolymerization, such as the improvement of light absorption and fast kinetics, with the benefits of $\mathrm{TiO}_{2}$ semiconductors: simple and low-cost process, no byproducts, and non-extractable PI residues in the polymer products. An emphasis on the $f$ $\mathrm{TiO}_{2}$ system allowed to go beyond the proof of concept. First, the scale-up of the process was demonstrated and then, experiments were carried out to prove the recyclability. In the future, we foresee that such $\mathrm{TiO}_{2}$ photoinitiating systems could be used for a broader range of waterinsoluble monomer dispersed into aqueous emulsions. In addition, new syntheses could also 
be envisaged such as polythiophene, poly(3,4-ethylenedioxythiophene), or polypyrrole via oxidative photopolymerization, proceeding through different mechanisms.

\section{Acknowledgement}

The authors gratefully acknowledge the French Agence Nationale de Recherche (ANR), Programme Chimie Durable-Industries-Innovation (CDII, ANR-2012-CDII-006-02) for funding. The authors thank Emeric Gras from Saint Gobain who provide the $f$-TiO2 sample (Quartzel PCO $\left.{ }^{\circledR}\right)$. Emeline Lobry acknowledges Dr Suqing Shi (College of Chemistry and Materials Science Northwest University, Xi'an, Shaanxi, China) for fruitful discussions.

KEYWORDS: miniemulsion, photopolymerization, photoinitiator, photocatalysis, titanium dioxide

\section{References}

[1] M. Schmitt, Macromol. Chem. Phys. 2012, 213, 1953.

[2] W. A. Green, Industrial Photoinitators, a Technical Guide, CRC Press, Taylor \& Francis Group, New York, USA, 2010.

[3] J. L. Aparicio, M. Elizalde, Packag. Tech. Sci. 2015, 28, 181.

[4] S. Dadashi-Silab, C. Aydogan, Y. Yagci, Polym. Chem. 2015, 6, 6595.

[5] J. P. Fouassier, J. Lalevée, Photoinitiators for Polymer Synthesis: Scope, Reactivity and Efficiency, Wiley-VCH Verlag GmbH \& Co. KGaA, Weinheim, Germany, 2012.

[6] M. Schmitt, Nanoscale 2015, 7, 9532.

[7] Z.-Y. Huang, T. Barber, G. Mills, M.-B. Morris, J. Phys. Chem. 1994, 98, 12746.

[8] I. G. Popović, L. Katsikas, H. Weller, Polym. Bull. 1994, 32, 597.

[9] J. C. Kuriacose, M. C. Markham, J. Phys. Chem. 1961, 65, 2232. 
[10] M. Yamamoto, G. Oster, J. Polym. Sci., Part A: Polym. Chem. 1966, 4, 1683.

[11] A. J. Hoffman, H. Yee, G. Mills, M. R. Hoffmann, J. Phys. Chem. 1992, 96, 5540.

[12] B. L. Funt, S.-R. Tan, J. Polym. Sci., Part A: Polym. Chem. 1984, 22, 605.

[13] O. Legrini, E. Oliveros, A. M. Braun, Chem. Rev. 1993, 93, 671.

[14] T. Oppenländer, Photochem. Purif. Water Air 2007, 189, Photochemical Purification of Water and Air: Advanced Oxidation Processes (AOPs): Principles, Reaction Mechanisms, Reactor Concepts, Wiley-VCH Verlag GmbH\&Co. KGaA, Weinheim, Germany, 2002.

[15] A. R. Ribeiro, O. C. Nunes, M. F. R. Pereira, A. M. T. Silva, Environ. Int. 2015, 75, 33.

[16] B. Kraeutler, H. Reiche, A. J. Bard, R. G. Hocker, J. Polym. Sci. Polym. Lett. Ed. $1979,17,535$.

[17] C. Damm, D. Völtzke, H.-P. Abicht, G. Israel, J. Photochem. Photobiol. A 2005, 174, 171.

[18] C. Damm, J. Photochem. Photobiol. A 2006, 181, 297.

[19] C. Damm, R. Herrmann, G. Israel, F. W. Müller, Dyes Pigments 2007, 74, 335.

[20] A. L. Stroyuk, V. M. Granchak, A. V. Korzhak, S. Y. Kuchmii, J. Photochem. Photobiol. A 2004, 162, 339.

[21] D. Yang, X. Ni, W. Chen, Z. Weng, J. Photochem. Photobiol. A 2008, 195, 323.

[22] J. Ye, X. Ni, C. Dong, J. Macromol. Sci. Part A 2005, 42, 1451.

[23] A. L. Stroyuk, I. V. Sobran, S. Y. Kuchmiy, J. Photochem. Photobiol. A 2007, 192, 98.

[24] S. Dadashi-Silab, A. M. Asiri, S. B. Khan, K. A. Alamry, Y. Yagci, J. Polym. Sci. Part A: Polym. Chem. 2014, 52, 1500.

[25] S. Dadashi-Silab, M. Atilla Tasdelen, A. Mohamed Asiri, S. Bahadar Khan, Y. Yagci, Macromol. Rapid Commun. 2014, 35, 454. 
[26] J. Yan, B. Li, F. Zhou, W. Liu, ACS Macro Lett. 2013, 2, 592.

[27] D. Zhang, J. Yang, S. Bao, Q. Wu, Q. Wang, Sci. Rep. 2013, 3, 1399.

[28] X. Ni, J. Ye, C. Dong, J. Photochem. Photobiol. Chem. 2006, 181, 19.

[29] C. Dong, X. Ni, J. Macromol. Sci. Part A 2004, 41, 547.

[30] Z. Wei, C. Zou, X. Ni, J. Appl. Polym. Sci. 2014, 131, n/a.

[31] X. Song, Y. Zhao, H. Wang, Q. Du, Langmuir 2009, 25, 4443.

[32] X. Song, G. Yin, Y. Zhao, H. Wang, Q. Du, J. Polym. Sci., PartA: Polym. Chem. 2009, 47, 5728

[33] R. L. Pozzo, M. A. Baltanás, A. E. Cassano, Catal. Today 1997, 39, 219.

[34] G. Li, K. A. Gray, Chem. Phys. 2007, 339, 173.

[35] T. Luttrell, S. Halpegamage, J. Tao, A. Kramer, E. Sutter, M. Batzill, Sci. Rep. 2014, 4, 4043.

Received: Month XX, XXXX; Revised: Month XX, XXXX; Published online:

((For PPP, use "Accepted: Month XX, XXXX" instead of "Published online")); DOI: 10.1002/marc.((insert number)) ((or ppap., mabi., macp., mame., mren., mats.)

Intensively investigated as photocatalysts for the photodegradation of persistent organic contaminants, $\mathrm{TiO}_{2}$ nanomaterials can be tamed to enable miniemulsion photopolymerization. In particular, colloidal and supported titania offer many advantages compared to conventional molecular photoinitiator: facile addition to the monomer dispersion, high surface-to-volume ratio, non migrating, no byproducts, simple and low cost process, and possible recovery/reuse.

E. Lobry, A. S. BT Bah, L. Vidal, E. Oliveros, A. M. Braun, A. Criqui, A. Chemtob*

Title Colloidal and Supported $\mathrm{TiO}_{2}$ : Towards Non-Extractable and Recyclable Photocatalysts for Radical Polymerizations in Aqueous Dispersed Media 


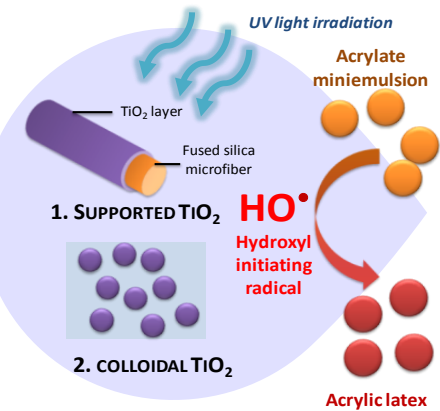


Supporting Information

for Macromol. Chem. Phys, DOI: 10.1002/macp.2013\#\#\#\#\#

Colloidal and Supported $\mathrm{TiO}_{2}$ : Towards Non-Extractable and Recyclable Photocatalysts for Radical Polymerizations in Aqueous Dispersed Media

Emeline Lobry, Abdoul Salam BT Bah, Loïc Vidal, Esther Oliveros, André M. Braun, Adrien Criqui, Abraham Chemtob*

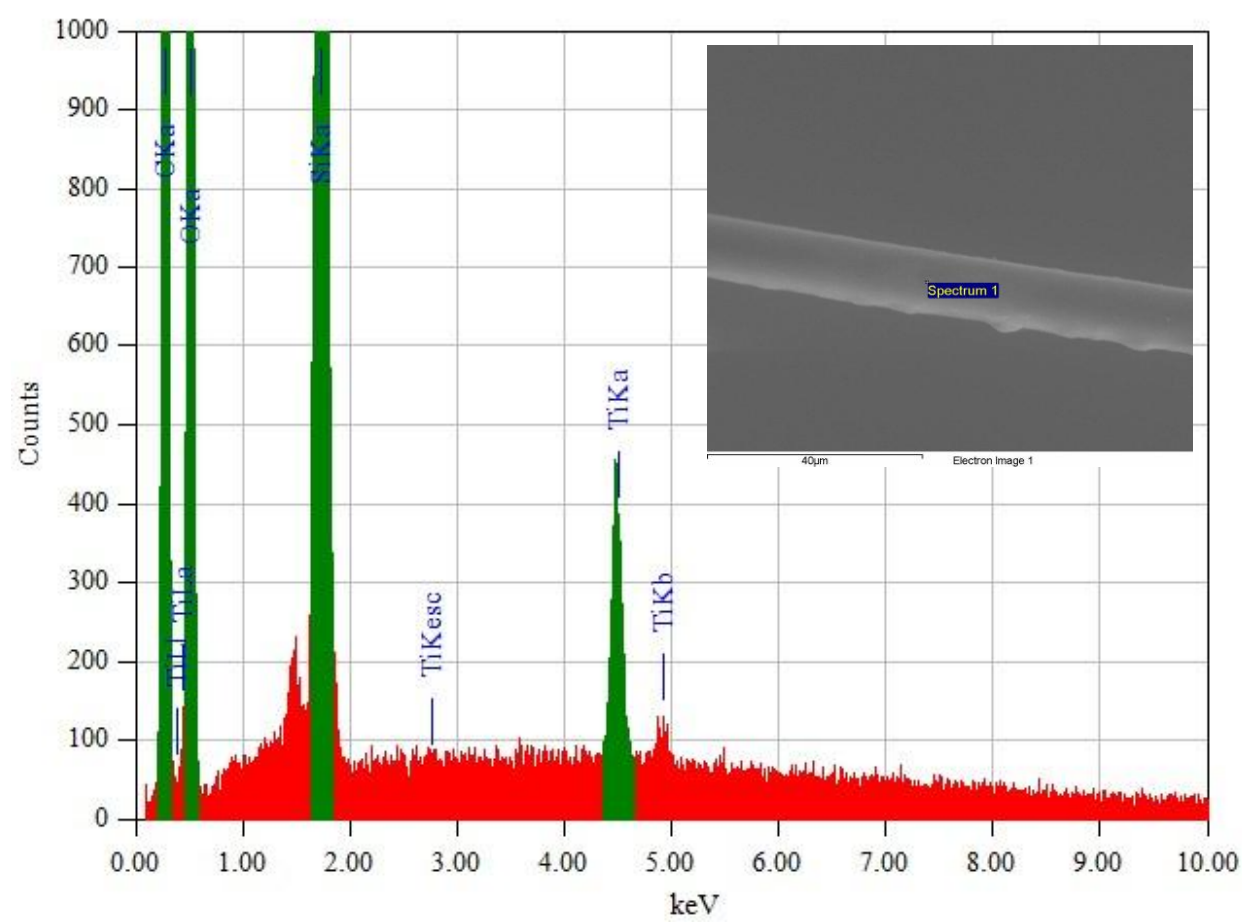

Figure S1. SEM picture and quantitative analysis of $f-\mathrm{TiO}_{2}$ 

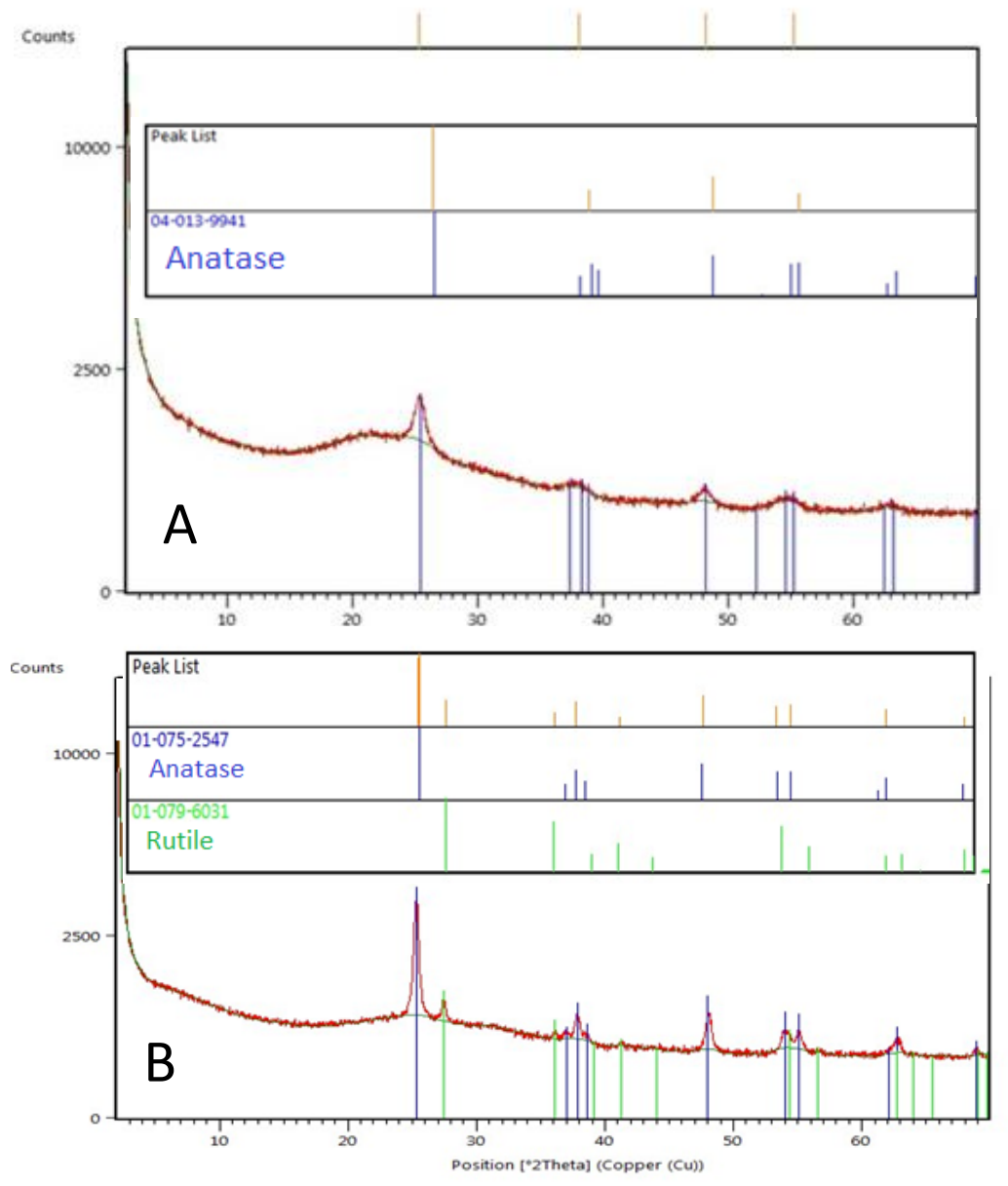

Figure S2. XRD pattern of $\boldsymbol{f}-\mathrm{TiO}_{2}(\operatorname{trace} \mathrm{A})$ and $\boldsymbol{c}-\mathrm{TiO}_{2}$ nanoparticles (trace $\mathrm{B}$ ) 


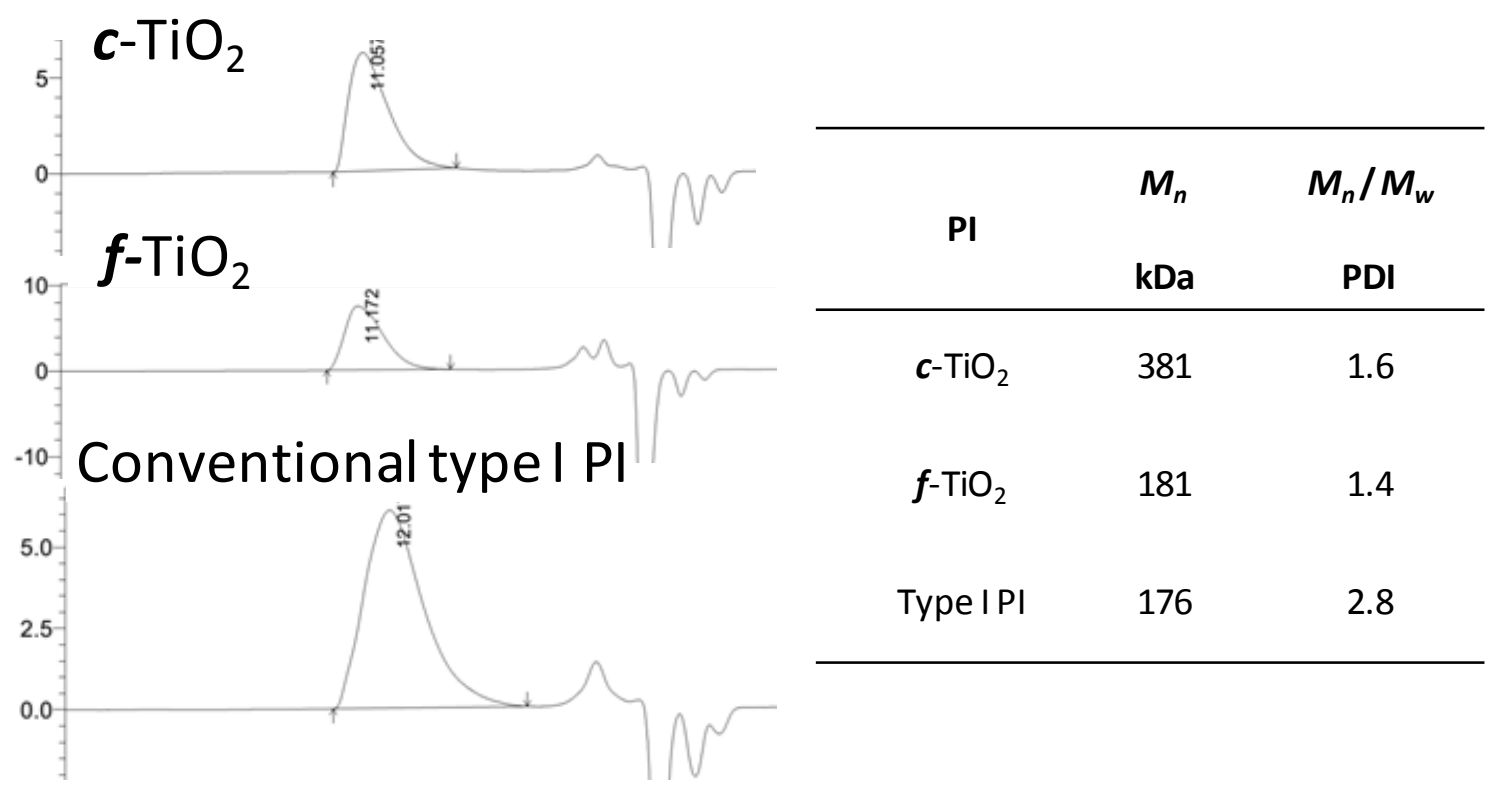

Figure S3. SEC traces of PMMA obtained by miniemulsion photopolymerization catalyzed by $\boldsymbol{c}-\mathrm{TiO}_{2}, \boldsymbol{f}-\mathrm{TiO}_{2}$ and a conventional type I PI (hydroxyacetophenone). Irradiation conditions: Hg-Xe lamp, $430 \mathrm{~mW} / \mathrm{cm}^{2}$, 310-600 nm, $10 \mathrm{~min}$ UV exposure. 